\title{
Current Topics and Perspectives in Surgical Management of Hepatocellular Carcinoma
}

\author{
Sebastian Lünse ${ }^{1}$ • Claus-Dieter Heidecke ${ }^{1}$ Lars Ivo Partecke ${ }^{2}$ \\ ${ }^{1}$ Department of General Surgery, Visceral, Thoracic and Vascular Surgery, \\ Universitätsmedizin Greifswald, Greifswald, Germany; ${ }^{2}$ Department of General, Visceral \\ and Thoracic Surgery, Helios Klinikum Schleswig, Schleswig, Germany
}

Author for correspondence: Sebastian Lünse, Department of General Surgery, Visceral, Thoracic and Vascular Surgery, Universitätsmedizin Greifswald, Germany.

Email: sebastian.luense@med.uni-greifswald.de

Doi: http://dx.doi.org/10.15586/hepatocellularcarcinoma.2019.ch6

\begin{abstract}
Hepatocellular carcinoma is among the leading causes of cancer-related mortality. Due to the numerous surgical and non-surgical therapeutic options, the treatment strategy requires an optimal selection of patients based on tumor stage and liver functional reserve. A potentially curative surgical resection or liver transplantation is only recommended for patients with early stage disease. In this chapter, we overview the current topics and perspectives in the surgical management of hepatocellular carcinoma by disease stage with a special focus on new surgical techniques and expanding range of indications outside of the accepted Barcelona Clinic Liver Cancer algorithm.
\end{abstract}

Keywords: BCLC staging system; hepatocellular carcinoma; laparoscopic liver resection; liver transplantation; surgical treatment.

In: Hepatocellular Carcinoma. Janina E.E. Tirnitz-Parker (Editor), Codon Publications, Brisbane, Australia. ISBN: 978-0-9944381-8-8. 2019; Doi: http://dx.doi.org/10.15586/ hepatocellularcarcinoma.2019

Copyright: The Authors.

License: This open access article is licensed under Creative Commons Attribution 4.0 International (CC BY 4.0). https://creativecommons.org/licenses/by-nc/4.0/ 


\section{INTRODUCTION}

Hepatocellular carcinoma (HCC) is among the leading causes of cancer-related death worldwide (1). Surgical resection or liver transplantation is the principal treatment option, depending on various factors, such as the liver functional reserve and tumor stage at the time of diagnosis. However, patients with HCC often present with late stage disease, which severely restricts the possibility for surgical resection. The Barcelona Clinic Liver Cancer (BCLC) staging system has become established as the most widely accepted staging system for HCC. In addition, the BCLC system is a clinical treatment guideline and comprises five stages related to the patient's performance, tumor condition, and liver functional reserve. Curative liver surgery is only recommended for early stages of HCC. In this chapter, we summarize the current role of surgical resection for HCC by disease stage in accordance with the BCLC treatment algorithm. Furthermore, we highlight the limitations of surgical resection and report data that support a treatment outside the accepted BCLC algorithm with a special focus for "advanced" but technically resectable HCC. Finally, we provide an overview on the ongoing developments of new surgical techniques, such as laparoscopic liver resection (LLR), robot-assisted liver resection (RALR), the associating liver partition, and portal vein ligation for staged hepatectomy (ALPPS) procedure, as well as perspectives in liver transplantation.

\section{CURRENT SURGICAL MANAGEMENT OF HCC}

Surgical resection or liver transplantation is the mainstay of potentially curative treatment for HCC. In addition to the surgical treatments or in patients with HCC who are not candidates for major liver surgery, there are various minimally invasive procedures besides systemic chemotherapy, including selective internal radiation therapy (SIRT), radiosurgery (Gamma Knife), transcatheter arterial chemoembolization (TACE), radiofrequency ablation (RFA), highly focused ultrasound (HIFU), microwave ablation (MWA), percutaneous ethanol injection (PEI), as well as irreversible electroporation (IRE). In this chapter, we focus on the current topics of surgical treatment for HCC at an early-, intermediate-, and advanced-stage based on the BCLC staging system. Furthermore, we discuss the current value of liver transplantation in the treatment of HCC.

\section{Preoperative assessment}

Staging of HCC is determined on the basis of size and number of tumors and the presence or absence of vascular invasion as well as extrahepatic lesions. The anatomic delineation of tumor extent is best achieved with dynamic multiphase computed tomography (CT), whereas the hepatic arterial phase is assessed separately from the portal venous phase with a late "wash-out" phase (2-4). Magnetic resonance imaging (MRI) appears to be more accurate in liver staging for HCC using multiphasic and multiparametric imaging by combining T1-, T2-, and diffusion-weighted imaging with dynamic multiphasic imaging (5-7). 
The rate of extrahepatic disease spread of HCC at diagnosisis overall low, and the recognized sites of metastatic spread are lung, bone, peritoneum, and adrenal glands. Although not generally recommended, the 18-fluorodeoxyglucose positron-emission tomography (FDG-PET) can be used for the detection of otherwise occult distant metastatic disease (8). However, the risk of extrahepatic spread is higher in patients with a large tumor $>5 \mathrm{~cm}$, and such patients warrant additional imaging studies or staging laparoscopy with intraoperative ultrasound (IOUS) prior to surgical resection (9). Another benefit of IOUS is the identification of major intrahepatic vascular structures, which can be used to guide segmental or non-anatomic resections (10).

According to the BCLC staging system, liver function is assessed on the basis of the Child-Pugh classification, the presence of portal hypertension, and the presence of elevated serum bilirubin concentrations (11). A scoring system for assessing the severity of chronic liver disease, and subsequently in prioritizing for receipt of a liver transplant, is the Model for End-Stage Liver Disease or MELD (12). Currently, this score is used by the United Network for Organ Sharing (UNOS) and Eurotransplant for prioritizing allocation of liver transplants $(12,13)$. The clearance of indocyanine green (ICG-15) at 15 min can be used as a defining criterion for the selection of patients as well as liver resection type $(14,15)$. Moreover, the newly developed LiMAx ${ }^{\circledR}$ (Humedics, Berlin, Germany) test, a ${ }^{13} \mathrm{C}$-labelled methacetin-based metabolic liver function capacity test, is a suitable diagnostic tool to predict the individual risk of postoperative liver failure after liver surgery (16).

\section{BCLC staging classification}

Since the staging system was first published in 1999, the BCLC staging system has emerged as a primary system for staging as well as a clinical guideline for the treatment of HCC (17). The BCLC staging system stratifies treatment algorithms based on the patient's performance status, the size and number of tumor nodules present, the presence of liver impairment, including portal hypertension, as well as degree of cirrhosis as measured by the Child-Pugh classification (Figure 1). The classification has been updated according to evidence-based data and is presently endorsed as the standard system for HCC management by the American Association for the Study of Liver Disease, American Gastroenterology Association, European Association for the Study of Liver and the European Organization for the Research and Treatment of Cancer (18-20). Nonetheless, the BCLC system has been heavily criticized for its extremely limited criteria for resection and its recommendations against potentially curative liver surgery for "advanced" but technically resectable HCC.

\section{Early-stage disease}

According to the BCLC algorithm, only patients with very early stage disease (BCLC 0), with a single lesion less than $2 \mathrm{~cm}$, no evidence of portal hypertension and normal bilirubin levels, are recommended to undergo liver resection. Patients with early-stage disease (BCLC A), defined as single or three nodules less than $3 \mathrm{~cm}$, fulfill the Milan criteria and are recommended to undergo liver 


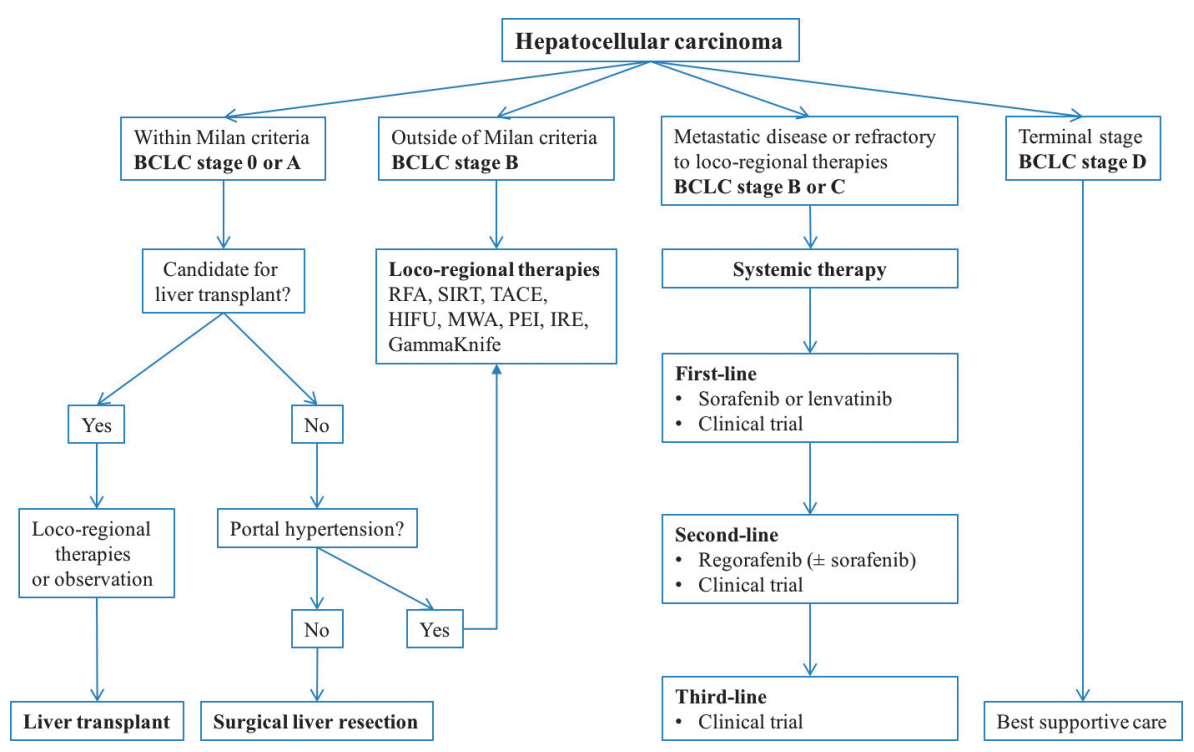

Figure 1 Treatment algorithm for hepatocellular carcinoma (1).

transplantation unless other comorbidities are present (21). Currently, there is an ongoing debate regarding surgical resection versus liver transplantation for (very) early-stage HCC. Concerning this matter, patients with preserved liver function and low-level cirrhosis have similar survival outcomes after liver surgery compared to liver transplantation (22). Due to low availability of organs, lifelong immunosuppression, and larger healthcare costs, orthotopic liver transplantation should be employed for patients with more severe cirrhosis (23).

According to the BCLC algorithm, PEI and RFA are recommended for early-stage disease. However, numerous studies revealed an improved survival outcome in patients who underwent surgical resection (24-26). A meta-analysis including 21,000 patients demonstrated a better overall survival as well as recurrence-free survival after surgical resection in comparison with RFA and/or PEI (24). Xu et al. confirmed this finding in another meta-analysis of over 2,500 patients (25). In addition, a prospective randomized trial including 235 patients who met Milan criteria showed a 5-year overall survival of $76.65 \%$ in the surgery group versus $54.78 \%$ in the RFA group (26). However, due to small residual liver volume, low liver functional reserve, or poor performance status, only 10-35\% of patients with very early- and early-stage disease underwent liver resection $(19,27)$. Nonetheless, these study data underline the advantages of surgical liver resection compared to local ablative therapies. Therefore, liver surgery should be offered in those patients with an early-stage HCC who can tolerate a major hepatic resection based on the underlying liver disease as well as comorbidities. Liver transplantation should be performed in patients with HCC and patients with lifelimiting cirrhosis. Otherwise, in patients with poor performance, local ablative therapies should be considered (23). 


\section{Intermediate-stage disease}

Intermediate-stage disease is defined by the BCLC staging system as patients with multinodular HCC and good performance status as well as no clinical evidence of portal vein invasion, nodal disease, or extrahepatic metastases. Patients with BCLC stage B are recommended for TACE, but several studies support surgical liver resection in intermediate stage HCC (28-31). A retrospective analysis of 393 patients by Zhong et al. confirmed a statistically significant improvement of median overall survival of patients who underwent surgical resection ( $59 \%$ vs. $29 \%$ at 3 years) compared to patients who underwent TACE (28). Another study from Ho et al. including 1,065 patients with multiple HCCs confirmed a better 5 -year survival rate (36.6\% vs. 11\%) in the liver surgery group compared to the TACE group (30). Furthermore, a prospective analysis of 168 patients with multiple HCC lesions greater than $5 \mathrm{~cm}$ showed the best 5 -year survival of $50.5 \%$ in patients who responded to neoadjuvant TACE followed by surgical liver resection (31). This finding was confirmed by a retrospective cohort study involving 110 patients (32). The median survival of patients who underwent TACE followed by liver resection was 47 months compared to 20 months in patients who received TACE alone. To summarize, a treatment strategy of TACE for downstaging followed by surgical liver resection seems to be beneficial for patients with large and multifocal, but resectable, HCCs falling within BCLC stage B.

\section{Advanced-stage disease}

The BCLC defines advanced-stage disease (stage C) as HCC with nodal and portal vein involvement, extrahepatic spread, or patients with poor performance status. According to the BCLC algorithm, the treatment of patients with stage C HCC is systemic sorafenib therapy (33). At present, systemic treatment of HCC is evolving rapidly, and three new multikinase inhibitors (i.e., regorafenib, lenvatinib, and cabozantinib) have been shown to be effective in phase 3 clinical trials (34). In the REFLECT trial, lenvatinib has shown to be non-inferior to sorafenib in a front-line setting (35). The treatment sequence of sorafenib plus regorafenib showed an important extension in overall survival of patients with advanced HCC, in the second-line setting (36). Based on the findings of CELESTIAL phase 3 trial, a treatment with cabozantinib resulted in longer overall survival and progression-free survival than placebo (37). Thus, the multikinase inhibitor cabozantinib seems to be an additional treatment option for use in adults with advanced HCC previously treated with sorafenib. Notably, sorafenib demonstrated no benefit in the adjuvant setting in HCC following surgical resection or local ablation (38). To date, no new drugs are approved for the adjuvant setting (39). However, there are numerous retrospective studies supporting surgical resection in patients with advanced HCC (40-46). A retrospective study by Ruzzenente et al. showed a statistically significant longer median survival (27 months vs. 12 months) in HCC patients with macroscopic vascular involvement who underwent liver surgery compared to systemic therapy only (41). A combination of local ablation via RFA or TACE and surgical resection seems to be a treatment option in patients with bilobar 
HCC metastases, but preserved liver function (44). This finding was confirmed by Liu et al. by a better survival outcome in selected patients with bilobar metastases and satisfactory liver function who underwent a combination of hepatic resection and ablation compared to non-resectional therapies (45). Generally, in areas with high incidence of HCC, such as Asia, surgical resection is commonly offered to patients with stage C disease $(46,47)$.

In summary, the retrospective literature highlights the value of a combined treatment strategy involving surgical liver resection and local ablation in a selected patient population of advanced HCC, particularly when liver function is preserved. Nonetheless, the survival of advanced HCC is still poor, and prospective randomized controlled studies are needed to obtain data with higher quality in matters of multimodality treatment.

\section{Liver transplantation}

The only potentially curable treatment of HCC is orthotopic liver transplantation, which allows not only the cure of the HCC but also the treatment of the underlying liver disease (48). However, due to the strict Milan criteria of liver transplantation in HCC patients (which include patients with one tumor $<50 \mathrm{~mm}$ or up to three tumors $<30 \mathrm{~mm}$ ) and the low availability of organs, only a small number of patients receive a liver transplant (21). Even though a 4-year survival rate of patients within Milan criteria is reported to be over $70 \%$ (21), approximately half of the patients develop liver cirrhosis post-transplantation (49). Nonetheless, a recent systemic review of 90 studies including 17,780 patients over a 15-year period confirmed the Milan criteria as major determinants of the prognosis of patients undergoing orthotopic liver transplantation for the treatment of HCC (50).

\section{Limitations of liver surgery}

Surgical liver resection should be performed in patients with HCC that is amenable to a negative resection margin (R0) and in patients with good liver functional reserve (23). Moreover, there is a limitation of resection by the need to maintain an adequate future liver remnant of commonly quoted 20\% (volumetric prediction) in patients without pre-existing liver dysfunction (51). Remarkably, the accepted future liver remnant values are more conservative in patients after chemotherapy treatment (30\%) and in patients with evidence of cirrhosis (40\%) (52). Therefore, these patients need a more conservative approach due to lower functional liver reserve. Patients with advanced cirrhosis or portal hypertension may be better managed by liver transplantation or ablative therapies. However, the risk of hepatic resection must be balanced by the patient's potential benefit from aggressive surgery.

\section{PERSPECTIVES IN SURGICAL MANAGEMENT OF HCC}

In the last two decades, there has been continuous development of new surgical techniques allowing for safer and more aggressive liver resections. Moreover, surgeons have developed a deeper understanding of physiology and functional 
reserve of the liver. Due to the broad criticism of the BCLC guidelines for recommending non-surgical treatment, expansion of surgical management for HCC should be explored. Here, we review significant advancements in surgical management of HCC including new techniques, particularly LLR, RALR, and the ALPPS procedure. Moreover, we recap extended criteria for liver transplantation beyond the Milan criteria.

\section{Laparoscopic liver resection}

Since the first use of laparoscopy for liver surgery in 1991 (53), several studies have shown the safety and efficacy of LLR with many advantages, including reduced blood loss and shorter hospital stay $(54,55)$. In addition, the International Survey on Technical Aspects of Laparoscopic Liver Resection (INSTALL) study revealed an increased number of LLR cases worldwide (56). The Second International Consensus Conference for Laparoscopic Liver Resection was held in Morioka, Japan, in 2014, with the dual goal of defining the current role of LLR and developing recommendations and guidelines (57). Despite a lack of high-level studies, minor LLR has become a standard practice. In contrast, the recommendation of the consensus meeting for major LLR was that surgeons undertaking these procedures should be experienced in both the liver surgery and advanced laparoscopy due to remaining risks associated with the newness of the procedure $(57,58)$. Furthermore, postoperative outcomes should be evaluated by randomized controlled trials and in registries.

In terms of the oncological outcome, several retrospective studies as well as meta-analysis demonstrated that LLR is non-inferior to laparotomy with fewer adverse effects, smaller amounts of blood loss, and shorter hospital stay (59-64). No significant differences between open and laparoscopic liver surgery were observed regarding overall survival of patients with early-stage HCC. Moreover, LLR seems to be superior in patients with impaired liver function $(65,66)$, and a better disease-free survival rate in advanced HCC patients was observed (67). Currently, a novel scoring system of surgical difficulty based on tumor factors (including location and relationship to large vessels) and liver functional reserve has been proposed as a training guideline $(68,69)$. In addition, this novel scoring model has been correlated with the postoperative outcome $(70,71)$. In summary, the laparoscopic approach will lead to expanding the surgical indications for HCC, especially in patients with chronic liver disease. Furthermore, a step-by-step training system for surgeons based on the novel difficulty scoring system can make this expansion safer and more effective for patients with HCC.

\section{Robot-assisted liver resection}

Since its inception in 2002, the innovative approach of RALR has gained worldwide acceptance (72-74). The indications for robotic liver resections are similar to those of LLRs, according to the Morioka consensus (57). In general, the indications are solitary lesions $<5 \mathrm{~cm}$ and located in liver segments 2-6 (75). Nonetheless, a number of reviews revealed extended indications for the robotic approach including every segment of the liver $(73,74,76)$. Contraindications 
are tumors with the invasion of major vascular structures or patients who are pneumoperitoneum-intolerant. A study by Lai et al. confirmed no significant differences in oncological outcomes between the robot-assisted and the conventional laparoscopic approach (77). Moreover, both techniques are similar in terms of blood loss, morbidity, and hospital stay, but prolonged operative times and increased costs were more evident in the robotic approach (76). The major advantage of RALR may lie in sectoral, segmental, or subsegmental resections in difficult-to-reach positions like posterior-superior segments and caudate lobe (78). Another benefit is the possibility of a shortened learning curve for complex liver resections based on the experiences in robot-assisted pancreatic resection (79). According to the currently available literature, RALR seems to be safe and feasible in selected patients with HCC. However, more prospective randomized studies are needed to determine the exact role of RALR within the treatment algorithm of HCC.

\section{Associating liver partition and portal vein ligation for staged hepatectomy}

The ALPPS procedure or "in situ split liver resection" is a novel two-stage surgical approach to induce rapid hypertrophy of the future liver remnantin a short period of time (80). The procedure is based on a combination of transection of the liver along the falciform ligament and dissection of the right portal veinin order to induce hypertrophy in the future liver remnant in patients undergoing an extended right hepatectomy. The ALPPS procedure might be considered in the following clinical scenarios: involvement of the right portal vein by HCC, progressive HCC with high risk for tumor progression between two stages of conventional surgical approach, and progressive HCC with extension to the vena cava or right heart atrium. Contraindications for ALPPS include inoperable hepatic metastasis in the future liver remnant, significant portal hypertension, and unresectable extrahepatic metastasis (81).

Nonetheless, ALPPS is associated with several adverse effects, including biliary leakage and intraperitoneal infection (82). An overall mortality rate of 59-64\% has been reported in association with ALPPS (83). According to the international ALPPS registry, the overall 90-day mortality rate was $8.8 \%$, in which $75 \%$ of deaths were related to postoperative liver failure. Moreover, patients with a model of end-stage liver disease (MELD) score of more than 10 showed a significantly increased mortality (84). For this reason, controversy exists regarding the use of ALPPS in real clinical practice, and patients should be carefully evaluated and selected in order to avoid postoperative small-forsize syndrome or acute liver failure (85). However, the evidence of oncological endpoints as well as technical availability of ALPPS is scarce up to now, and recent studies reported a perioperative mortality rate of $31 \%$ for HCC patients (86). In summary, the ALPPS procedure should be considered only in a highly selected patient population and should only be performed in highly specialized centers for liver surgery. Further studies are needed to determine the criteria for use of ALPSS and to define its value compared to other treatment algorithms of HCC. 


\section{Perspectives in liver transplantation-extended criteria}

Since its establishment by Mazzaferro et al. in 1996 (21), the Milan criteria have been applied widely around the world in the selection of patients for orthotopic liver transplantation. However, the Milan criteria are very restrictive concerning post-transplant recurrence rates and could be expanded, as long as patient outcome is not impaired. The University of California San Francisco (USCF) criteria are the most widely accepted for the expansion of the Milan criteria: a solitary tumor $\leq 65 \mathrm{~mm}$, or two to three tumors $\leq 45 \mathrm{~mm}$, and total tumor diameter $\leq 80 \mathrm{~mm}$, without vascular invasion or distant metastasis (87). According to Yao et al., the USCF 1-year and 5-year survival rates from lifetime data of 70 patients over a 12 -year period were 90 and $75 \%$, respectively (87). Moreover, the disease recurrence rates were comparable to those of the Milan criteria (88). Currently, further extended criteria for the selection of patients with HCC beyond the Milan criteria are subject of ongoing research. Assessment of the two clinical biomarkers, alpha-fetoprotein ( $<200 \mathrm{ng} / \mathrm{mL})$ and des-gamma carboxyprothrombin $(<400 \mathrm{mAU} / \mathrm{mL})$, showed an improved selection of patients with HCC for liver transplantation (89-91). A study by DuBay et al. confirmed excellent postliver-transplantation survival rates of patients with any HCC size and number, when an aggressive bridge-to-transplant therapy was applied and a poorly differentiated tumor was ruled out by liver biopsy (92). Tumor growth beyond the acceptable size can cause a drop out from the waiting list for transplantation. Importantly, liver resection prior to transplantation does not increase the morbidity or impair long-term survival following liver transplantation in selected patients (93).

However, excessive expansion of inclusion criteria will result in an increase in waiting time and a deterioration of survival among patients on the waiting list (94). Thus, the decision for a liver transplantation beyond the Milan criteria should be based on a case-by-case consideration, balancing the operative risk versus the potential survival benefit. Moreover, liver resection should be considered as a bridge-to-transplant option in highly selected patients with HCC.

\section{CONCLUSION}

HCC is a tumor with highly variable biology that often occurs in the setting of chronic liver disease. Patients often present with late stage disease, which excludes surgical resection from the treatment options. In this chapter, we have highlighted the current topics and perspectives in surgical management of HCC. Treatment strategies require optimal selection of therapies based on various tumor factors and liver functional reserve. The introduction of new surgical techniques, especially the laparoscopic approach; the combination of surgery with ablative therapies; and the expansion of indications for surgery beyond the conservative BCLC algorithm as well as beyond the Milan criteria have increased the variety of surgical treatment options for carefully selected patients with HCC. However, regarding the complexity of all treatment options, more detailed, rigorous studies are needed to determine evidence-based guidelines. 
Conflict of interest: The authors declare no potential conflict of interest with respect to research, authorship, and/or publication of this manuscript.

Copyright and permission statement: To the best of our knowledge, the materials included in this chapter do not violate copyright laws. All original sources have been appropriately acknowledged and/or referenced. Where relevant, appropriate permissions have been obtained from the original copyright holders(s).

\section{REFERENCES}

1. Forner A, Reig M, Bruix J. Hepatocellular carcinoma. Lancet. 2018;391(10127):1301-14. http:// dx.doi.org/10.1016/S0140-6736(18)30010-2

2. Murakami T, Kim T, Kawata S, Kanematsu M, Federle MP, Hori M, et al. Evaluation of optimal timing of arterial phase imaging for the detection of hypervascular hepatocellular carcinoma by using triple arterial phase imaging with multidetector-row helical computed tomography. Invest Radiol. 2003;38(8):497-503. http://dx.doi.org/10.1097/01.rli.0000074584.12494.e3

3. Iannaccone R, Laghi A, Catalano C, Rossi P, Mangiapane F, Murakami T, et al. Hepatocellular carcinoma: Role of unenhanced and delayed phase multi-detector row helical CT in patients with cirrhosis. Radiology. 2005;234(2):460-7. http://dx.doi.org/10.1148/radiol.2342031202

4. Laghi A, Iannaccone R, Rossi P, Carbone I, Ferrari R, Mangiapane F, et al. Hepatocellular carcinoma: Detection with triple-phase multi-detector row helical CT in patients with chronic hepatitis. Radiology. 2003;226(2):543-9. http://dx. doi.org/10.1148/radiol.2262012043

5. Rode A, Bancel B, Douek P, Chevallier M, Vilgrain V, Picaud G, et al. Small nodule detection in cirrhotic livers: Evaluation with US, spiral CT, and MRI and correlation with pathologic examination of explanted liver. J Comput Assist Tomogr. 2001;25(3):327-36. http://dx.doi. org/10.1097/00004728-200105000-00001

6. Burrel M, Llovet JM, Ayuso C, Iglesias C, Sala M, Miquel R, et al. MRI angiography is superior to helical CT for detection of HCC prior to liver transplantation: An explant correlation. Hepatology. 2003;38(4):1034-42. http://dx.doi.org/10.1002/hep.1840380430

7. Kim YK, Kim CS, Chung GH, Han YM, Lee SY, Chon SB, et al. Comparison of gadobenate dimeglumine-enhanced dynamic MRI and 16-MDCT for the detection of hepatocellular carcinoma. AJR Am J Roentgenol. 2006;186(1):149-57. http://dx.doi.org/10.2214/AJR.04.1206

8. Lunse S, Doring P, Heidecke CD, Partecke LI. Giant hepatocellular carcinoma with bone metastasis in a young adult, emerged from pigmented adenoma with beta-Catenin activation: A case report. Int J Surg Case Rep. 2017;36:18-21. http://dx.doi.org/10.1016/j.ijscr.2017.04.001

9. Montorsi M, Santambrogio R, Bianchi P, Opocher E, Cornalba GP, Dapri G, et al. Laparoscopy with laparoscopic ultrasound for pretreatment staging of hepatocellular carcinoma: A prospective study. J Gastrointest Surg. 2001;5(3):312-15. http://dx.doi.org/10.1016/S1091-255X(01)80053-6

10. Bismuth H, Castaing D, Garden OJ. The use of operative ultrasound in surgery of primary liver tumors. World J Surg. 1987;11(5):610-14. http://dx.doi.org/10.1007/BF01655836

11. Bruix J, Reig M, Sherman M. Evidence-based diagnosis, staging, and treatment of patients with hepatocellular carcinoma. Gastroenterology. 2016;150(4):835-53. http://dx.doi.org/10.1053/j. gastro.2015.12.041

12. Kamath PS, Kim WR, Advanced Liver Disease Study G. The model for end-stage liver disease (MELD). Hepatology. 2007;45(3):797-805. http://dx.doi.org/10.1002/hep.21563

13. Wiesner R, Edwards E, Freeman R, Harper A, Kim R, Kamath P, et al. Model for end-stage liver disease (MELD) and allocation of donor livers. Gastroenterology. 2003;124(1):91-6. http://dx.doi. org/10.1053/gast.2003.50016

14. Audebert C, Vignon-Clementel IE. Model and methods to assess hepatic function from indocyanine green fluorescence dynamical measurements of liver tissue. Eur J Pharm Sci. 2018;115:304-19. http://dx.doi.org/10.1016/j.ejps.2018.01.008 
15. Sakka SG. Assessment of liver perfusion and function by indocyanine green in the perioperative setting and in critically ill patients. J Clin Monit Comput. 2018;32(5):787-96. http://dx.doi.org/10.1007/ s10877-017-0073-4

16. Stockmann M, Lock JF, Malinowski M, Niehues SM, Seehofer D, Neuhaus P. The LiMAx test: A new liver function test for predicting postoperative outcome in liver surgery. HPB (Oxford). 2010;12(2):139-46. http://dx.doi.org/10.1111/j.1477-2574.2009.00151.x

17. Llovet JM, Bru C, Bruix J. Prognosis of hepatocellular carcinoma: The BCLC staging classification. Semin Liver Dis. 1999;19(3):329-38. http://dx.doi.org/10.1055/s-2007-1007122

18. Llovet JM, Burroughs A, Bruix J. Hepatocellular carcinoma. Lancet. 2003;362(9399):1907-17. http:// dx. doi.org/10.1016/S0140-6736(03)14964-1

19. Bruix J, Sherman M, American Association for the Study of Liver D. Management of hepatocellular carcinoma: An update. Hepatology. 2011;53(3):1020-2. http://dx.doi.org/10.1002/hep.24199

20. Llovet JM, Di Bisceglie AM, Bruix J, Kramer BS, Lencioni R, Zhu AX, et al. Design and endpoints of clinical trials in hepatocellular carcinoma. J Natl Cancer Inst. 2008;100(10):698-711. http://dx.doi. org/10.1093/jnci/djn134

21. Mazzaferro V, Regalia E, Doci R, Andreola S, Pulvirenti A, Bozzetti F, et al. Liver transplantation for the treatment of small hepatocellular carcinomas in patients with cirrhosis. N Engl J Med. 1996;334(11):693-9. http://dx.doi.org/10.1056/NEJM199603143341104

22. Slotta JE, Kollmar O, Ellenrieder V, Ghadimi BM, Homayounfar K. Hepatocellular carcinoma: Surgeon's view on latest findings and future perspectives. World J Hepatol. 2015;7(9):1168-83. http://dx.doi.org/10.4254/wjh.v7.i9.1168

23. Chawla A, Ferrone C. Hepatocellular carcinoma surgical therapy: Perspectives on the current limits to resection. Chin Clin Oncol. 2018;7(5):48. http://dx.doi.org/10.21037/cco.2018.08.12

24. Ni JY, Xu LF, Sun HL, Zhou JX, Chen YT, Luo JH. Percutaneous ablation therapy versus surgical resection in the treatment for early-stage hepatocellular carcinoma: A meta-analysis of 21,494 patients. J Cancer Res Clin Oncol. 2013;139(12):2021-33. http://dx.doi.org/10.1007/s00432-013-1530-1

25. Xu G, Qi FZ, Zhang JH, Cheng GF, Cai Y, Miao Y. Meta-analysis of surgical resection and radiofrequency ablation for early hepatocellular carcinoma. World J Surg Oncol. 2012;10:163. http://dx.doi. org/10.1186/1477-7819-10-163

26. Huang J, Yan L, Cheng Z, Wu H, Du L, Wang J, et al. A randomized trial comparing radiofrequency ablation and surgical resection for HCC conforming to the Milan criteria. Ann Surg. 2010;252(6): 903-12. http://dx.doi.org/10.1097/SLA.0b013e318lefc656

27. Llovet JM, Zucman-Rossi J, Pikarsky E, Sangro B, Schwartz M, Sherman M, et al. Hepatocellular carcinoma. Nat Rev Dis Primers. 2016;2:16018. http://dx.doi.org/10.1038/nrdp.2016.18

28. Zhong JH, Xiang BD, Gong WF, Ke Y, Mo QG, Ma L, et al. Comparison of long-term survival of patients with BCLC stage B hepatocellular carcinoma after liver resection or transarterial chemoembolization. PLoS One. 2013;8(7):e68193. http://dx.doi.org/10.1371/journal.pone.0068193

29. Torzilli G, Donadon M, Marconi M, Palmisano A, Del Fabbro D, Spinelli A, et al. Hepatectomy for stage B and stage C hepatocellular carcinoma in the Barcelona Clinic Liver Cancer classification: Results of a prospective analysis. Arch Surg. 2008;143(11):1082-90. http://dx.doi.org/10.1001/ archsurg. 143.11.1082

30. Ho MC, Huang GT, Tsang YM, Lee PH, Chen DS, Sheu JC, et al. Liver resection improves the survival of patients with multiple hepatocellular carcinomas. Ann Surg Oncol. 2009;16(4):848-55. http:// dx.doi.org/10.1245/s10434-008-0282-7

31. Luo J, Peng ZW, Guo RP, Zhang YQ, Li JQ, Chen MS, et al. Hepatic resection versus transarterial lipiodol chemoembolization as the initial treatment for large, multiple, and resectable hepatocellular carcinomas: A prospective nonrandomized analysis. Radiology. 2011;259(1):286-95. http://dx.doi. org/10.1148/radiol.10101072

32. Chen J, Lai L, Lin Q, Huang W, Cai M, Zhu K, et al. Hepatic resection after transarterial chemoembolization increases overall survival in large/multifocal hepatocellular carcinoma: A retrospective cohort study. Oncotarget. 2017;8(1):408-17. http://dx.doi.org/10.18632/oncotarget.13427

33. Kane RC, Farrell AT, Madabushi R, Booth B, Chattopadhyay S, Sridhara R, et al. Sorafenib for the treatment of unresectable hepatocellular carcinoma. Oncologist. 2009;14(1):95-100. http://dx.doi. org/10.1634/theoncologist.2008-0185 
34. Tovoli F, Negrini G, Benevento F, Faggiano C, Goio E, Granito A. Systemic treatments for hepatocellular carcinoma: Challenges and future perspectives. Hepat Oncol. 2018;5(1):HEP01. http://dx.doi. org/10.2217/hep-2017-0020

35. Kudo M, Finn RS, Qin S, Han KH, Ikeda K, Piscaglia F, et al. Lenvatinib versus sorafenib in first-line treatment of patients with unresectable hepatocellular carcinoma: A randomised phase 3 non-inferiority trial. Lancet. 2018;391(10126):1163-73. http://dx.doi.org/10.1016/S0140-6736(18)30207-1

36. Bruix J, Qin S, Merle P, Granito A, Huang YH, Bodoky G, et al. Regorafenib for patients with hepatocellular carcinoma who progressed on sorafenib treatment (RESORCE): A randomised, doubleblind, placebo-controlled, phase 3 trial. Lancet. 2017;389(10064):56-66. http://dx.doi.org/10.1016/ S0140-6736(16)32453-9

37. Abou-Alfa GK, Meyer T, Cheng AL, El-Khoueiry AB, Rimassa L, Ryoo BY, et al. Cabozantinib in patients with advanced and progressing hepatocellular carcinoma. N Engl J Med. 2018;379(1):54-63. http://dx.doi.org/10.1056/NEJMoal717002

38. Bruix J, Takayama T, Mazzaferro V, Chau GY, Yang J, Kudo M, et al. Adjuvant sorafenib for hepatocellular carcinoma after resection or ablation (STORM): A phase 3, randomised, doubleblind, placebo-controlled trial. Lancet Oncol. 2015;16(13):1344-54. http://dx.doi.org/10.1016/ S1470-2045(15)00198-9

39. Germano D, Daniele B. Systemic therapy of hepatocellular carcinoma: Current status and future perspectives. World J Gastroenterol. 2014;20(12):3087-99. http://dx.doi.org/10.3748/wjg.v20.i12.3087

40. Pawlik TM, Poon RT, Abdalla EK, Ikai I, Nagorney DM, Belghiti J, et al. Hepatectomy for hepatocellular carcinoma with major portal or hepatic vein invasion: Results of a multicenter study. Surgery. 2005;137(4):403-10. http://dx.doi.org/10.1016/j.surg.2004.12.012

41. Ruzzenente A, Capra F, Pachera S, Iacono C, Piccirillo G, Lunardi M, et al. Is liver resection justified in advanced hepatocellular carcinoma? Results of an observational study in 464 patients. J Gastrointest Surg. 2009;13(7):1313-20. http://dx.doi.org/10.1007/s11605-009-0903-x

42. Amini N, Ejaz A, Spolverato G, Maithel SK, Kim Y, Pawlik TM. Management of lymph nodes during resection of hepatocellular carcinoma and intrahepatic cholangiocarcinoma: A systematic review. J Gastrointest Surg. 2014;18(12):2136-48. http://dx.doi.org/10.1007/s11605-014-2667-1

43. Xiaohong S, Huikai L, Feng W, Ti Z, Yunlong C, Qiang L. Clinical significance of lymph node metastasis in patients undergoing partial hepatectomy for hepatocellular carcinoma. World J Surg. 2010;34(5):1028-33. http://dx.doi.org/10.1007/s00268-010-0400-0

44. Zhang $\mathrm{T}$, Zeng Y, Huang J, Liao M, Wu H. Combined resection with radiofrequency ablation for bilobar hepatocellular carcinoma: A single-center experience. J Surg Res. 2014;191(2):370-8. http:// dx.doi.org/10.1016/j.jss.2014.03.048

45. Liu CL, Fan ST, Lo CM, Ng IO, Poon RT, Wong J. Hepatic resection for bilobar hepatocellular carcinoma: Is it justified? Arch Surg. 2003;138(1):100-4. http://dx.doi.org/10.1001/archsurg.138.1.100

46. Ho MC, Hasegawa K, Chen XP, Nagano H, Lee YJ, Chau GY, et al. Surgery for intermediate and advanced hepatocellular carcinoma: A consensus report from the 5th Asia-Pacific primary liver cancer expert meeting (APPLE 2014). Liver Cancer. 2016;5(4):245-56. http://dx.doi.org/10.1159/000449336

47. Mittal S, El-Serag HB. Epidemiology of hepatocellular carcinoma: Consider the population. J Clin Gastroenterol. 2013;47(Suppl):S2-6. http://dx.doi.org/10.1097/MCG.0b013e3182872f29

48. Cucchetti A, Vitale A, Cescon M, Gambato M, Maroni L, Ravaioli M, et al. Can liver transplantation provide the statistical cure? Liver Transpl. 2014;20(2):210-17. http://dx.doi.org/10.1002/lt.23783

49. Cescon M, Cucchetti A, Ravaioli M, Pinna AD. Hepatocellular carcinoma locoregional therapies for patients in the waiting list. Impact on transplantability and recurrence rate. J Hepatol. 2013;58(3): 609-18. http://dx.doi.org/10.1016/j.jhep.2012.09.021

50. Mazzaferro V, Bhoori S, Sposito C, Bongini M, Langer M, Miceli R, et al. Milan criteria in liver transplantation for hepatocellular carcinoma: An evidence-based analysis of 15 years of experience. Liver Transpl. 2011;17(Suppl 2):S44-57. http://dx.doi.org/10.1002/lt.22365

51. Chapelle T, Op De Beeck B, Huyghe I, Francque S, Driessen A, Roeyen G, et al. Future remnant liver function estimated by combining liver volumetry on magnetic resonance imaging with total liver function on ( $99 \mathrm{~m}$ ) Tc-mebrofenin hepatobiliary scintigraphy: Can this tool predict post-hepatectomy liver failure? HPB (Oxford). 2016;18(6):494-503. http://dx.doi.org/10.1016/j.hpb.2015.08.002 
52. Zorzi D, Laurent A, Pawlik TM, Lauwers GY, Vauthey JN, Abdalla EK. Chemotherapy-associated hepatotoxicity and surgery for colorectal liver metastases. Br J Surg. 2007;94(3):274-86. http://dx.doi. org/10.1002/bjs.5719

53. Reich H, McGlynn F, DeCaprio J, Budin R. Laparoscopic excision of benign liver lesions. Obstet Gynecol. 1991;78(5 Pt 2):956-8.

54. Ciria R, Cherqui D, Geller DA, Briceno J, Wakabayashi G. Comparative short-term benefits of laparoscopic liver resection: 9000 cases and climbing. Ann Surg. 2016;263(4):761-77. http://dx.doi. org/10.1097/SLA.0000000000001413

55. Kaneko H, Otsuka Y, Kubota Y, Wakabayashi G. Evolution and revolution of laparoscopic liver resection in Japan. Ann Gastroenterol Surg. 2017;1(1):33-43. http://dx.doi.org/10.1002/ags3.12000

56. Hibi T, Cherqui D, Geller DA, Itano O, Kitagawa Y, Wakabayashi G. International survey on technical aspects of laparoscopic liver resection: A web-based study on the global diffusion of laparoscopic liver surgery prior to the 2nd International Consensus Conference on Laparoscopic Liver Resection in Iwate, Japan. J Hepatobiliary Pancreat Sci. 2014;21(10):737-44. http://dx.doi.org/10.1002/ jhbp. 141

57. Wakabayashi G, Cherqui D, Geller DA, Buell JF, Kaneko H, Han HS, et al. Recommendations for laparoscopic liver resection: A report from the second international consensus conference held in Morioka. Ann Surg. 2015;261(4):619-29.

58. Berardi G, Van Cleven S, Fretland AA, Barkhatov L, Halls M, Cipriani F, et al. Evolution of laparoscopic liver surgery from innovation to implementation to mastery: Perioperative and oncologic outcomes of 2,238 patients from 4 European specialized centers. J Am Coll Surg. 2017;225(5):639-49. http://dx.doi.org/10.1016/j.jamcollsurg.2017.08.006

59. Zhou YM, Shao WY, Zhao YF, Xu DH, Li B. Meta-analysis of laparoscopic versus open resection for hepatocellular carcinoma. Dig Dis Sci. 2011;56(7):1937-43. http://dx.doi.org/10.1007/ s10620-011-1572-7

60. Kim H, Suh KS, Lee KW, Yi NJ, Hong G, Suh SW, et al. Long-term outcome of laparoscopic versus open liver resection for hepatocellular carcinoma: A case-controlled study with propensity score matching. Surg Endosc. 2014;28(3):950-60. http://dx.doi.org/10.1007/s00464-013-3254-3

61. Chen J, Bai T, Zhang Y, Xie ZB, Wang XB, Wu FX, et al. The safety and efficacy of laparoscopic and open hepatectomy in hepatocellular carcinoma patients with liver cirrhosis: A systematic review. Int J Clin Exp Med. 2015;8(11):20679-89.

62. Takahara T, Wakabayashi G, Beppu T, Aihara A, Hasegawa K, Gotohda N, et al. Long-term and perioperative outcomes of laparoscopic versus open liver resection for hepatocellular carcinoma with propensity score matching: A multi-institutional Japanese study. J Hepatobiliary Pancreat Sci. 2015;22(10):721-7. http://dx.doi.org/10.1002/jhbp.276

63. Sposito C, Battiston C, Facciorusso A, Mazzola M, Muscara C, Scotti M, et al. Propensity score analysis of outcomes following laparoscopic or open liver resection for hepatocellular carcinoma. Br J Surg. 2016;103(7):871-80. http://dx.doi.org/10.1002/bjs.10137

64. Landi F, De' Angelis N, Scatton O, Vidal X, Ayav A, Muscari F, et al. Short-term outcomes of laparoscopic vs. open liver resection for hepatocellular adenoma: A multicenter propensity score adjustment analysis by the AFC-HCA-2013 study group. Surg Endosc. 2017;31(10):4136-44. http://dx.doi. org/10.1007/s00464-017-5466-4

65. Morise Z, Ciria R, Cherqui D, Chen KH, Belli G, Wakabayashi G. Can we expand the indications for laparoscopic liver resection? A systematic review and meta-analysis of laparoscopic liver resection for patients with hepatocellular carcinoma and chronic liver disease. J Hepatobiliary Pancreat Sci. 2015;22(5):342-52. http://dx.doi.org/10.1002/jhbp.215

66. Otsuka Y, Kaneko H. Laparoscopic liver resection in the treatment of HCC with liver cirrhosis: Would it provide superiority to conventional open hepatectomy? Hepatobiliary Surg Nutr. 2017;6(5):356-8. http://dx.doi.org/10.21037/hbsn.2017.06.02

67. Cheung TT, Dai WC, Tsang SH, Chan AC, Chok KS, Chan SC, et al. Pure laparoscopic hepatectomy versus open hepatectomy for hepatocellular carcinoma in 110 patients with liver cirrhosis: A propensity analysis at a single center. Ann Surg. 2016;264(4):612-20. http://dx.doi.org/10.1097/ SLA. 0000000000001848 
68. Hasegawa Y, Wakabayashi G, Nitta H, Takahara T, Katagiri H, Umemura A, et al. A novel model for prediction of pure laparoscopic liver resection surgical difficulty. Surg Endosc. 2017;31(12):5356-63. http://dx.doi.org/10.1007/s00464-017-5616-8

69. Kawaguchi Y, Fuks D, Kokudo N, Gayet B. Difficulty of laparoscopic liver resection: Proposal for a new classification. Ann Surg. 2018;267(1):13-17. http://dx.doi.org/10.1097/SLA.0000000000002176

70. Tanaka S, Kubo S, Kanazawa A, Takeda Y, Hirokawa F, Nitta H, et al. Validation of a difficulty scoring system for laparoscopic liver resection: A multicenter analysis by the Endoscopic Liver Surgery Study Group in Japan. J Am Coll Surg. 2017;225(2):249-58 el. http://dx.doi.org/10.1016/j. jamcollsurg.2017.03.016

71. Lee SY, Goh BK, Chan CY. Clinical utility of the difficulty scoring system for predicting surgical time of laparoscopic liver resection. J Laparoendosc Adv Surg Tech A. 2016;26(12):1019-20. http://dx.doi. org/10.1089/lap.2016.0415

72. Giulianotti PC, Coratti A, Angelini M, Sbrana F, Cecconi S, Balestracci T, et al. Robotics in general surgery: Personal experience in a large community hospital. Arch Surg. 2003;138(7):777-84. http:// dx.doi.org/10.1001/archsurg.138.7.777

73. Qiu J, Chen S, Chengyou D. A systematic review of robotic-assisted liver resection and meta-analysis of robotic versus laparoscopic hepatectomy for hepatic neoplasms. Surg Endosc. 2016;30(3):862-75. http://dx.doi.org/10.1007/s00464-015-4306-7

74. Salloum C, Lim C, Malek A, Compagnon P, Azoulay D. Robot-assisted laparoscopic liver resection: A review. J Visc Surg. 2016;153(6):447-56. http://dx.doi.org/10.1016/j.jviscsurg.2016.08.005

75. Buell JF, Cherqui D, Geller DA, O'Rourke N, Iannitti D, Dagher I, et al. The international position on laparoscopic liver surgery: The Louisville Statement, 2008. Ann Surg. 2009;250(5):825-30. http:// dx.doi.org/10.1097/SLA.0b013e3181b3b2d8

76. Nota CL, Rinkes IHB, Molenaar IQ, van Santvoort HC, Fong Y, Hagendoorn J. Robot-assisted laparoscopic liver resection: A systematic review and pooled analysis of minor and major hepatectomies. HPB (Oxford). 2016;18(2):113-20. http://dx.doi.org/10.1016/j.hpb.2015.09.003

77. Lai EC, Tang CN. Long-term survival analysis of robotic versus conventional laparoscopic hepatectomy for hepatocellular carcinoma: A comparative study. Surg Laparosc Endosc Percutan Tech. 2016;26(2):162-6. http://dx.doi.org/10.1097/SLE.0000000000000254

78. Giulianotti PC, Tzvetanov I, Jeon H, Bianco F, Spaggiari M, Oberholzer J, et al. Robot-assisted right lobe donor hepatectomy. Transpl Int. 2012;25(1):e5-9. http://dx.doi.org/10.1111/j.1432-2277.2011 $.01373 . x$

79. Zeh HJ 3rd, Bartlett DL, Moser AJ. Robotic-assisted major pancreatic resection. Adv Surg. 2011;45:323-40. http://dx.doi.org/10.1016/j.yasu.2011.04.001

80. Vennarecci G, Grazi GL, Santoro R, Ettorre GM. A room for the alpps procedure in patients with HCC. Int J Surg. 2015;13:90-1. http://dx.doi.org/10.1016/j.ijsu.2014.11.054

81. Alvarez FA, Ardiles V, Sanchez Claria R, Pekolj J, de Santibanes E. Associating liver partition and portal vein ligation for staged hepatectomy (ALPPS): Tips and tricks. J Gastrointest Surg. 2013;17(4):814-21. http://dx.doi.org/10.1007/s11605-012-2092-2

82. Bertens KA, Hawel J, Lung K, Buac S, Pineda-Solis K, Hernandez-Alejandro R. ALPPS: Challenging the concept of unresectability-A systematic review. Int J Surg. 2015;13:280-7. http://dx.doi. org/10.1016/j.ijsu.2014.12.008

83. Schnitzbauer AA, Lang SA, Goessmann H, Nadalin S, Baumgart J, Farkas SA, et al. Right portal vein ligation combined with in situ splitting induces rapid left lateral liver lobe hypertrophy enabling 2-staged extended right hepatic resection in small-for-size settings. Ann Surg. 2012;255(3):405-14. http://dx.doi.org/10.1097/SLA.0b013e31824856f5

84. Schadde E, Raptis DA, Schnitzbauer AA, Ardiles V, Tschuor C, Lesurtel M, et al. Prediction of mortality after ALPPS stage-1: An analysis of 320 patients from the international ALPPS registry. Ann Surg. 2015;262(5):780-5; discussion 5-6. http://dx.doi.org/10.1097/SLA.0000000000001450

85. Ielpo B, Quijano Y, Vicente E. Pearls and pitfalls on ALPPS procedure: New complications in a new technique. Updates Surg. 2014;66(2):159-61. http://dx.doi.org/10.1007/s13304-014-0249-0 
86. Daher S, Massarwa M, Benson AA, Khoury T. Current and future treatment of hepatocellular carcinoma: An updated comprehensive review. J Clin Transl Hepatol. 2018;6(1):69-78. http://dx.doi. org/10.14218/JCTH.2017.00031

87. Yao FY, Ferrell L, Bass NM, Watson JJ, Bacchetti P, Venook A, et al. Liver transplantation for hepatocellular carcinoma: Expansion of the tumor size limits does not adversely impact survival. Hepatology. 2001;33(6):1394-403. http://dx.doi.org/10.1053/jhep.2001.24563

88. Chan SC, Fan ST. Selection of patients of hepatocellular carcinoma beyond the Milan criteria for liver transplantation. Hepatobiliary Surg Nutr. 2013;2(2):84-8.

89. Li C, Zhang Z, Zhang P, Liu J. Diagnostic accuracy of des-gamma-carboxy prothrombin versus alphafetoprotein for hepatocellular carcinoma: A systematic review. Hepatol Res. 2014:44(10):E11-25. http://dx.doi.org/10.1111/hepr.12201

90. Takada Y, Uemoto S. Liver transplantation for hepatocellular carcinoma: The Kyoto experience. J Hepatobiliary Pancreat Sci. 2010;17(5):527-32. http://dx.doi.org/10.1007/s00534-009-0162-y

91. Zheng SS, Xu X, Wu J, Chen J, Wang WL, Zhang M, et al. Liver transplantation for hepatocellular carcinoma: Hangzhou experiences. Transplantation. 2008;85(12):1726-32. http://dx.doi.org/10.1097/ TP.0b013e31816b67e4

92. DuBay D, Sandroussi C, Sandhu L, Cleary S, Guba M, Cattral MS, et al. Liver transplantation for advanced hepatocellular carcinoma using poor tumor differentiation on biopsy as an exclusion criterion. Ann Surg. 2011;253(1):166-72. http://dx.doi.org/10.1097/SLA.0b013e31820508f1

93. Belghiti J, Cortes A, Abdalla EK, Regimbeau JM, Prakash K, Durand F, et al. Resection prior to liver transplantation for hepatocellular carcinoma. Ann Surg. 2003;238(6):885-92; discussion 92-3. http://dx.doi.org/10.1097/01.sla.0000098621.74851.65

94. Volk ML, Vijan S, Marrero JA. A novel model measuring the harm of transplanting hepatocellular carcinoma exceeding Milan criteria. Am J Transplant. 2008;8(4):839-46. http://dx.doi. org/10.1111/j.1600-6143.2007.02138.x 